\title{
DDE/OR/00033-T 668 \\ ADSORPTION OF RADIONUCLIDES ON MINERALS -STUDIES ILLUSTRATING THE EFFECT OF SOLID PHASE SELECTIVITY AND OF MECHANISMS CONTROLLING SORPTION PROCESSES
}

\author{
*Bernard Netus

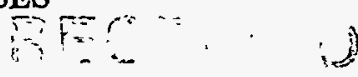

Howard University, Department of Chemical Engineering, Washington, D.C. 20059

Abstract

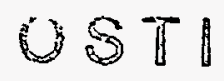

Currently, extensive research is being done on the geochemistry of Yucca Mountain, Nevada. The purpose of this research is to determine whether this location would be suitable as a permanent high-level radioactive waste repository. Site characterization tests must prove that Yucca Mountains' geology will safely isolate radioactive waste from the environment for at least 10,000 years before approval is granted. In order for this to occur, it is necessary to study the sorptive properties of the host rock, and its selectivity in sorption of solutions containing multiple radionuclides. Validation of this must occur, because in the case of a catastrophic leak, the host rock must have properties that will retard the migration of radionuclides. Columnar experimental techniques were employed using goethite, (a hydrous iron oxide), beidellite (clay mineral), \& 'nonscents' (a zeolitized volcanic tuff) as sorbents. These sorbents were used to measure the isotherms of an identical binary solution (Ni-Sr) to illustrate the selectivity that occurs in different minerals. In beidellite, the sorption process was ideal, while for 'nonscents' there was a strong preference for $\mathrm{Sr}^{2+}$. The sorption process was modeled (Ni-Sr 'Nonscents') using ion exchange theory as the mechanism. Validation of ion-exchange as the mechanisms for the two sorbents are well known in literature. ${ }^{2}$ In goethite, the sorption of $\mathrm{Ni}$-Sr showed a complete preference for $\mathrm{Ni}^{2+}$ at a $\mathrm{pH}$ of 7 . In various other systems for goethite, $\mathrm{Co}-\mathrm{Ni}(\mathrm{pH}=7$ ) was ideal (no selectivity) where the ratios in the solid and solution phases were relatively equal. Conversely in the case of the $\mathrm{Pb}-\mathrm{Ni}$ system, the $\mathrm{Pb}^{2+}$ ion predominated completely in the solid phase over $\mathrm{Ni}^{2+}$ at a pH of 5.5. Noting the strong effect of $\mathrm{pH}$ on the sorption process in goethite, the selectivity could not necessarily be credited to ion-exchange because. of possible exclusion from charged sites at low $\mathrm{pH}$ values.

\section{Introduction}

Ever since the dawn of the atomic age, the permanent disposal of our nation's high-level nuclear waste has been a complex undertaking. To deal with this dilemma the U.S. Department of Energy has embarked on the unprecedented task of siting and developing a geologic repository that must safely contain these wastes for at least 10,000 years. The isolation of wastes will occur through a multiple barriered system that will include engineered and natural barriers. Engineered barriers would be the waste package \& repository, and natural barrier will include the 'host rock' or geologic environment in which the repository is built.

As a possible site for the repository, site characterization tests must prove that Yucca Mits' geology would prevent the migration of radionuclides to the accessible environment. Most scientists believe that the only plausible scenario for this occurring is through groundwater transport. In realistically considering the proposed goal of 10,000 years, one must postulate that the engineered barriers will eventually deteriorate. Thus one must study the sorptive properties of the host rock, and its selectivity in solutions containing multiple radionuclides in the case of a catastrophic leak.

The present study involving the notion of selectivity occurring in solutions containing multiple radionuclides is quite unique. Earlier experimental studies conducted by Los Alamos scientists ${ }^{5}$ involved only single solute mixtures that did not take into account of sorption characteristics in a multi-solute ionic mixture. Solid-phase selectivity is a very important phenomenon that must not be ignored. This is so because the presence of one solute ion that may be highly favored in the sorbent phase may considerably reduce the sorption capacity of the other solute ion(s). Thus, to not overestimate a given radionuclides' sorption capacity on a certain mineral, one must thoroughly examine parameters that effect these processes.

\section{MASTER}




\section{Theory}

Traditionally, scientists (Geochemists) have used mathematical models such as Linear, Langmuir, Freudlich, and modified Langmuir to describe sorption isotherms. Parameters used in these models $\mathrm{KD}_{\mathrm{D}}$ and $\beta$ are not fundamental constants, but vary with experimental conditions. Examples of this are the solid to liquid ratio, and the initial compositions of the competing solute ions in both the sorbent and liquid phases. These conditions make these simplified models only relevant for physical adsorption processes. Through theoretical formulations by Gaines and Thomas ${ }^{2}$, demonstrated the use of fundamental thermodynamic constants such as the rational selectivity coefficient $\&$ solid-phase activity coefficients to model sorption of radionuclides on minerals.

The proposed mechanism to describe the phase equilibrium theory is ion-exchange. Ion-exchange is defined as 'the reversible interchange of ions between a solid and a liquid phase in which there is no permanent change in the structure of the solid'. 6 The fundamental basis for ion-exchangers states that the surface of the solid has fixed 'charged sites' that allow for 'exchanging' by cations present in the external aqueous solution. The first significant contributions to ion exchange have generally been attributed to Thompson and Way in 1850, prior to the postulation by Arthenius in 1885, the concept of ionization. These investigators experimentally showed the elution or 'regeneration' step when the cation was returned to its original state. Lemberg in 1870 clearly illustrated the stoichiometry and reversibility of ion-exchange in the transformation of the mineral leucite $\left(\mathrm{K}_{2} \mathrm{O} \cdot \mathrm{Al}_{2} \mathrm{O}_{3} \cdot 4 \mathrm{SiO}_{2}\right)$ to analcite $\left(\mathrm{Na}_{2} \mathrm{O} \cdot \mathrm{Al}_{2} \mathrm{O}_{3} \cdot 4 \mathrm{SiO}_{2} \cdot 2 \mathrm{H}_{2} \mathrm{O}\right)$ by leaching leucite with a sodium chloride solution. Rinsing with a potassium chloride solution restored the leucite.

A simple binary exchange process in which ion $A$ is initially in aqueous phase, exchanging with ion $B$ on the solid phase, can be written as:

$$
v_{B} A^{v^{A+}}(a q)+v_{A} \bar{B}^{v_{B^{+}}} \Leftrightarrow v_{B} \bar{A}^{v_{A^{+}}}+v_{A} B^{v_{B^{+}}}(a q)
$$

Where vA and vB are stoichiometric coefficients of ions $\mathrm{A}$ and $\mathrm{B}, \bar{A}$ and $\bar{B}$ are solute ions in the solid phase. The thermodynamic equilibrium constant for the above binary ion-exchange can be expressed

$$
K_{A B}^{E}=\frac{\left(\bar{X}_{A} \bar{\gamma}_{A}\right)^{v_{B}} \cdot\left(C_{B} \gamma_{B}\right)^{v_{A}}}{\left(\bar{X}_{B} \bar{\gamma}_{B}\right)^{v_{A}} \cdot\left(C_{A} \gamma_{A}\right)^{v_{1}}}
$$

Where $\overline{\mathrm{X}}_{\Lambda}$ and $\overline{\mathrm{X}}_{\mathrm{B}}$ are equivalent or charge fractions of ions $\mathrm{A}$ and $\mathrm{B}$ in the solid phase, $\bar{\gamma}_{i}$ and $\gamma_{i}$ are ionic activity coefficients in the solid and liquid phases respectively. $C_{A}$ and $C_{B}$ are concentrations of solute ions in the liquid phase (moles $L^{-1}$ ). Next, the rational selectivity coefficient can be defined as:

$$
K_{A B}^{r}=\frac{\bar{X}_{A}^{v_{A}} \cdot\left(C_{B} \gamma_{B}\right)^{v_{A}}}{\bar{X}_{B}^{v_{A}} \cdot\left(C_{A} \gamma_{A}\right)^{v_{A}}}
$$

This coefficient can be directly calculated from experimental sorption measurements. The rational selectivity coefficient varies as a function of solid-phase composition. Activity coefficients in these equations are computed from the theoretical formulation by Debye \& Huckel. They were able to show that in dilute solutions the activity coefficient $\gamma_{i}$ of an ion species $i$ is computed by the following equation:

$$
\log \gamma_{t}=\frac{-A Z_{t}^{2} \mu^{1 / 2}}{1+B d_{i} \mu^{1 / 2}}
$$


Where $A$ and $B$ are constants, $Z_{i}$ is the valency of the two ions, $d_{i}$ is the effective distance of the ions and $\mu$ is the ionic strength. Expanding on the theoretical development of Gaines and Thomas, the themodynamic equilibrium constant can be expressed as an integral of the rational selectivity coefficient.

$$
\ln K_{A B}^{E}=\left(v_{B}-v_{A}\right)+\int_{0}^{1} \ln K_{A B}^{r} \cdot d \bar{X}_{B}
$$

The individual ionic activity coefficients in the solid phase can be expressed as:

$$
\begin{aligned}
& v_{B} \ln \bar{\gamma}_{A}=\left(v_{B}-v_{A}\right) \bar{X}_{B}-\bar{X}_{B} \ln K_{A B}^{r}+\int_{0}^{\bar{X}_{B}} \ln K_{A B}^{r} \cdot d \bar{X}_{B} \\
& v_{A} \ln \bar{\gamma}_{B}=\left(v_{A}-v_{B}\right) \bar{X}_{A}+\bar{X}_{A} \ln K_{A B}^{r}-\int_{\bar{X}_{B}}^{1} \ln K_{A B}^{r} \cdot d \bar{X}_{B}
\end{aligned}
$$

Knowing the thermodynamic equilibrium constant, the Standard Gibbs Free Energy of the exchange reaction can be computed by:

$$
\Delta G_{A B}=-R T \ln K_{A B}^{E}
$$

The Gibbs free energy is used to indicate the preference that the sorbent has for competing solute ions by relating the selectivity coefficients to the free-energy changes occurring when ions are exchanged.

\section{Experimental}

The sorbents used, (described in Tables 1-3) prior to experimental study were crushed, washed, and sieved to a Tyler mesh particle size of $(-20+100)$ and $(-70+200)$ except for 'nonscents' which was already in granular form. Employing a continuous upward flow technique illustrated in Figure \#1, approximately 95g of the sorbent for goethile \& $5 \mathrm{~g}$ for beidellite and 'nonscents' were placed and secured in a Pyrex glass column. This was done by fitting a porous filter cloth at each end. The column could now be connected to a peristaltic pump where the flow rate of could be controlled.

Prcceding the sorption process, the sorbent was first converted to a homogenic form $\left(\mathrm{NH}_{4}{ }^{+}\right)$for the purpose of removing extraneous chemicals by 'washing' it with a $4 \mathrm{~L}$ solution of $1 \mathrm{M} \mathrm{NH}_{4} \mathrm{Cl}$. Next, the bed was rid free of the electrolyte solution with deionized water. This was assured by testing the conductivity of the deionized water through the extraction of a $10 \mathrm{ml}$ sample from the column.

A sorption run could now be implemented with varying compositions of the ionic pairs of $\mathrm{Ni}-\mathrm{Sr}, \mathrm{Pb}=\mathrm{Ni}$. \& Co-Ni. All solutions were carefully prepared using analytical grade chemicals $\left[\mathrm{Pb}\left(\mathrm{NO}_{3}\right)_{2}, \mathrm{CoCl}_{2} * 6 \mathrm{H}_{2} \mathrm{O}\right.$, $\mathrm{NiCl}_{2}{ }^{*} 6 \mathrm{H}_{2} \mathrm{O}, \mathrm{SrCl}_{2}{ }^{*} 6 \mathrm{H}_{2} \mathrm{O}$ ] for pre-determined concentrations $(0.075 \mathrm{~N}$ for $\mathrm{Pb}-\mathrm{Ni} \& 0.3 \mathrm{~N}$ for $\mathrm{Co}-\mathrm{Ni} \& \mathrm{Ni}-\mathrm{Sr})$ and pH's (5.4-5.6 for $\mathrm{Pb}-\mathrm{Ni} \&$ 7.0-7.2 for $\mathrm{Co}-\mathrm{Ni} \& \mathrm{Ni}-\mathrm{Sr}$ on goethite). From prior investigations the sorption capacity in goethite has shown to have a direct relationship to $\mathrm{pH}$ (i.e higher $\mathrm{pH}$ more sorption, while on beidellite $\&$ 'nonscents' there is no effect). To ensure equilibrium between the two phases, the sorption solutions were continuously recirculated at a flow rate of $25-30 \mathrm{ml} / \mathrm{hr}$ for a period of 3 to 4 weeks for 'nonscents \& beidellite \& 8 to 10 weeks for goethite. Attempting to keep the driving force constant to ensure maximum sorption, the 'old' solutions were replaced with fresh solutions every two weeks. Following the end of the sorption run, the bed was washed free of any adhering electrolyte with deionized water, and the sorbed cations $\left(\mathrm{Sr}^{2+}, \mathrm{Pb}^{2+}, \mathrm{Ni}^{2+}, \& \mathrm{Co}^{2+}\right)$ were eluted with a $4.5 \mathrm{pH}$ solution of deionized water for goethite and a $1 \mathrm{M} \mathrm{NH} 4 \mathrm{Cl}$ solution for beidellite and 'nonscents'. 
Table \#I

X-Ray Diffraction Mineral Analysis of Nonscents Sample

$\begin{array}{lr}\text { Alpha Quartz } & 19 \% \\ \text { Cristobalite } & 2 \% \\ \text { Plagioclase- } & 19 \% \\ \text { Feldspar } & \\ \text { Clinoptilolite } & 51 \% \\ \text { Alpha Iron } & 7 \% \\ \text { Clay Minerals } & 2 \%\end{array}$

Table \#2

(Mineralogical Properties of Goethite)

Goethite, $\mathrm{FeO}(\mathrm{OH})$

\section{Hardness: 5-5.5}

Specific Gravity: 3.3 to 4.3

Color and Streak: Blackish brown to yellow or reddish brown to brownish yellow in massive and earthy forms.Brownish yellow, orange-yellow

Chemistry: Pure goethite is usually close to $\mathrm{FeO}(\mathrm{OH})$ in composition.

Diagnostic features: Distinguished from romanechite and colloform hematite by streak and color, upon dissolving in $\mathrm{HCl}$, colors the solution yellow.

Occurrence, associations, and uses: Most of the common yellow-brown and brown ferric oxides usually known as limonite properly belong to this species. Most goethite has been formed as the result of the chemical weathering of iron minerals, such as siderite, pyrite, magnetite, and glauconite, under oxidizing conditions at ordinary temperatures. It also has been formed by direct precipitation from marine or meteoric waters in bogs and lagoons.

Table \#3

(Mineralogical Properties of Beidellite)

Beidellite, $(\mathrm{Na}, \mathrm{Ca})_{0.3} \mathrm{Al}_{2}(\mathrm{Si}, \mathrm{Al})_{4} \mathrm{O}_{10}\left(\mathrm{OH}_{2}\right)^{\star} \mathrm{H}_{2} \mathrm{O}$

\section{Hardness: $1-2$}

Density: Variable, 2-3

Color-Luster: White, reddish, brownish gray. Waxy to vitreous, also dull

Diagnostic features: N/A

Occurrence, associations, and uses: Occurs mainly as a constituent of bentonitic clay deposits or as a hydrothermal alteration product in ore veins. Typical occurrences are found in Los Angeles and Sierra counties, California; at the Castle Dome mine, Gila County, Arizona; at Beidell, Saguache County, and at other places in Colorado; in Tooele and Utah counties, Utah; at the Black Jack mine, Owyhee County, Idaho. 
Originally $1 \mathrm{M} \mathrm{NH}_{4} \mathrm{Cl}$ at a $\mathrm{pH}$ of 4.5 was used to elute cations from goethite, but through investigation it was found that $\mathrm{H}^{+}$ion was involved in the exchange process, not $\mathrm{NH}_{4}{ }^{+}$. This was proven through the fact that the $\mathrm{pH}$ of the eluted fractions increased in the range of 5.2 to 5.7 (eg. when a solution loses $\mathrm{H}^{+}$ions the $\mathrm{pH}$ increases). Similarly, when the sorption solution is passed through the bed, the $\mathrm{pH}$ of the solution decreased (eg. the cation under study $\mathrm{Pb}^{2+} \ldots$ sorbed on the soil, exchanging with the $\mathrm{H}^{+}$ion, thus decreasing the $\mathrm{pHI}$ by increasing the amount of hydrogen ions in the solution).

The eluted fractions were collected in portions of $2 \mathrm{~L}$ and analyzed for the concentration of each cation using the instrumentation method of Atomic Absorption Spectrophotometry. From the data collected(ppm mg/L), the sorption isotherms were created by plotting the value of the ion in the solid phase $\bar{x}$ vs. the value of the same ion in the solution phase $\mathrm{x}$. This is done through the following set of calculations.

$$
m e q=\operatorname{ppm}(m g / L) \times \operatorname{volume}(L) \times[\text { charge }(\text { valency }) / \text { molecular.wt }]
$$

Once this is done for all the fractions collected (5-10), one can obtain the total sorbent phase content of each cation:

$$
\sum \bar{C}_{P b}, \sum \bar{C}_{C o}, \sum \bar{C}_{N i}, \sum \bar{C}_{S r}
$$

Next, the total sorbent phase content of both pairs were computed by adding each individual pair together. Finally with that answer, the value of the predominant ion was divided over the total sum (sorbent phase content of both ions). Now the data could be curve fitted to produce an isotherm.

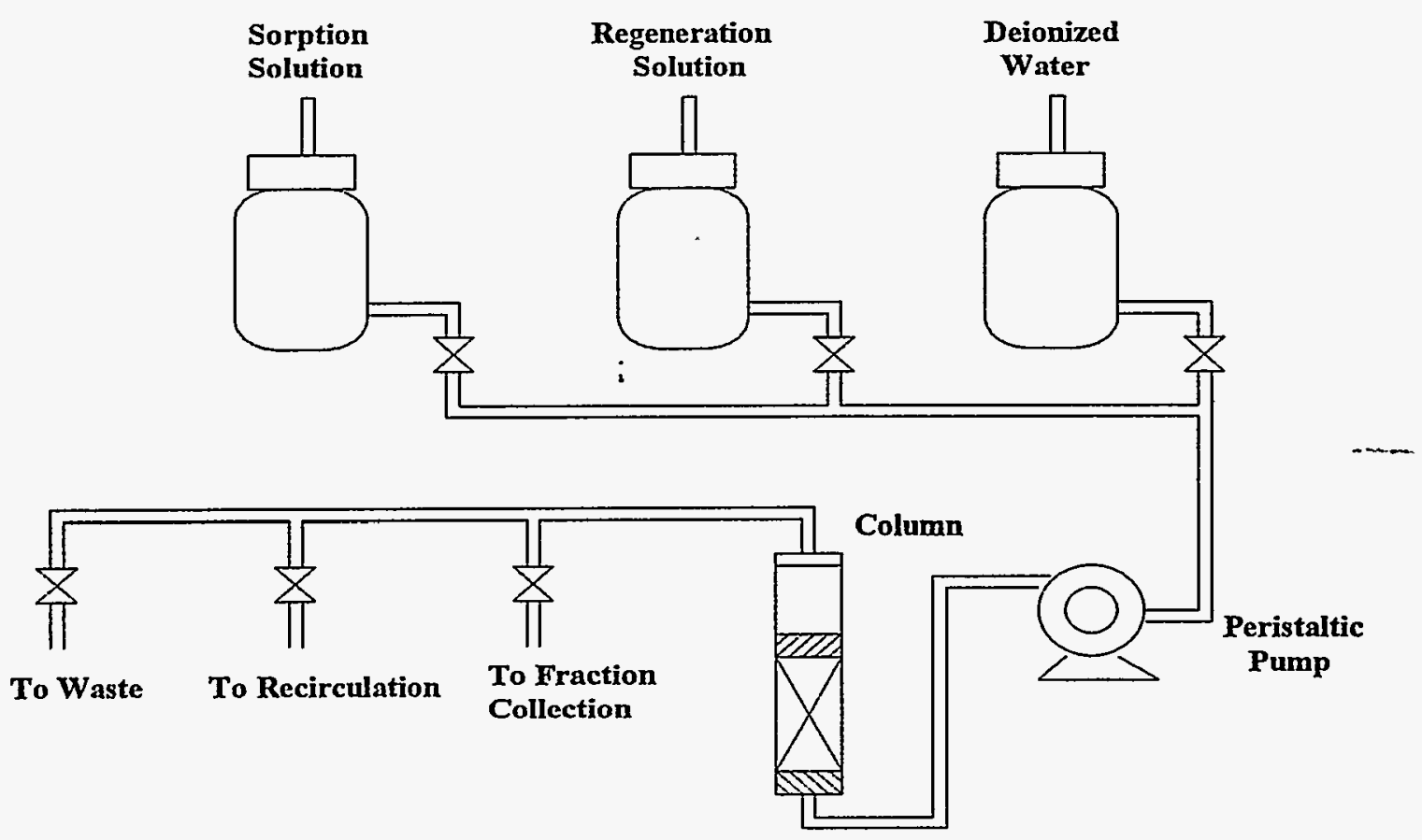

Figure \#I Schematic of Experimental Setup 


\section{Results and Discussion}

The experimental results clearly show and prove the effect of solid phase selectivily for sorption on minerals, and the disparate behavior of identical ionic pairs in different minerals. According to the isotherm shown in Figure \#2, 'nonscents' is shown to have preference for $\mathrm{Sr}^{2+}$ in the presence of $\mathrm{Ni}^{2+}$ shown by a positive deviation from ideality. In Figure \#3 the sorption processes for both systems (shown by a $45^{0}$ line) were ideal. Ideal systems where the ratios of each system were the same in the solid phase as they were in the solution phase. In Figure \#4, the illustration depicts the complete preference for $\mathrm{Ni}^{2+}$ in the presence of $\mathrm{Sr}^{2+}$ at a $\mathrm{pH}$ of 7 . The possible effect of $\mathrm{pH}$ of sorption on goethite was evident in Figure $\$ 5$. Here the $\mathrm{Pb}^{2+}$ ion sorbed exclusively over $\mathrm{Ni}^{2+}$ at a pH of 5.6 whereas the sorption for the remaining two systems, $\mathrm{Ni}-\mathrm{Co} \& \mathrm{Ni}$-Sr were performed at a pH of 7. As of today, it is not conclusive of the mechanism which controlls sorption on iron oxides. A final determination could not state whether the selectivity of $\mathrm{Pb}$ over $\mathrm{Ni}$ was through ion-exchange, or through the fact of possible exclusion of $\mathrm{Ni}^{2+}$ from charged sites at a $\mathrm{pH}$ of 5.6. There are several theories about modeling sorption processes on iron oxides such as surface complexation modeling, but as of today neither that nor ionexchange has been proven to a high degree of certainty.

Using the ion-exchange phase equilibrium formulation developed by Gaines and Thomas, (shown in eq. 2-7) the isotherm data of Ni-Sr 'nonscents' could be modeled (for nonideal behavior). The activity coefficients for $\mathrm{Ni} \& \mathrm{Sr}$ in the liquid phase were calculated using eq. 4 to be 0.258 \& 0.224 respectively. These values were used to calculate the rational selectivity coefficients as a function of the solid-phase composition of $\mathrm{Ni}^{2+}$, illustrated in Figure \#6. This plot confirms the selectivity of $\mathrm{Sr}^{2+}$ over $\mathrm{Ni}^{2+}$ (values greater than 1), and shows the dependence of $\mathrm{K}^{\mathrm{r}}$ on the solid phase fraction of $\mathrm{Ni}^{2+}$. Utilizing the plot of the $\ln$ of the rational selectivity coefficients vs. the solid phase fraction of $\mathrm{Ni}^{2+}$, the curve obtained was integrated between 0 and 1 , and that value was used in eq. 5 to determine the thermodynamic equilibrium constant which is 133 . From eq. $6 \& 7$, the values of the solid-phase activity coefficients for $\mathrm{Ni} \& \mathrm{Sr}$ were computed and plotted vs. the solid-phase fraction of $\mathrm{Ni}^{2+}$, represented in Figure \#7. The value for the thermodyamic equilibrium constant along with the solidphase activity coefficients can be used to predict multi-sorption mixtures of the constituent ionic pair (Ni-Sr) along with other ionic species. Similarly, the equilibrium constant can be used to predict sorption isotherms at any anion concentration desired, most likely one that would be relevant to operating repository conditions. Finally, the Gibbs Free Energy of the exchange reaction was computed using eq. 8 to be $-2.91 \mathrm{kcal} / \mathrm{gmole}$.

\section{Conclusions}

The isotherms of the various systems clearly showed the effect of selectivity in the sorption process in different ionic pairs \& for a similar ionic pair in different minerals. With extreme cases such as this, the effect of solid-phase selectivity of solutions containing multiple radionuclides in different minerals should not be ignored. If a radioactive mixture of $\mathrm{Ni}^{2+}$ and $\mathrm{Sr}^{2+}$ leaked from the proposed repository, surrounded by 'nonscents' as thehost rock, the $\mathrm{Sr}$ ion would be sufficiently retarded. In turn the $\mathrm{Ni}^{2+}$ ion will not sorb, and would eventually migrate far enough to cause contamination. Thus, to ensure that the geology of Yucca Mountain will thwart the migration of radionuclides, the site characterization studies must show a complete knowledge of the sorption capacities \& selectivities of every mineral for every combination of the elements that will be there.

\section{Acknowledgement}

This research project was conducted under the guidance of Dr. M. Gopala Rao, and funded by the Nuclear Regulatory Commissions' Historically Black Colleges and Universities Faculty/Student Research Participation Program, administered by ORISE/SEED. 


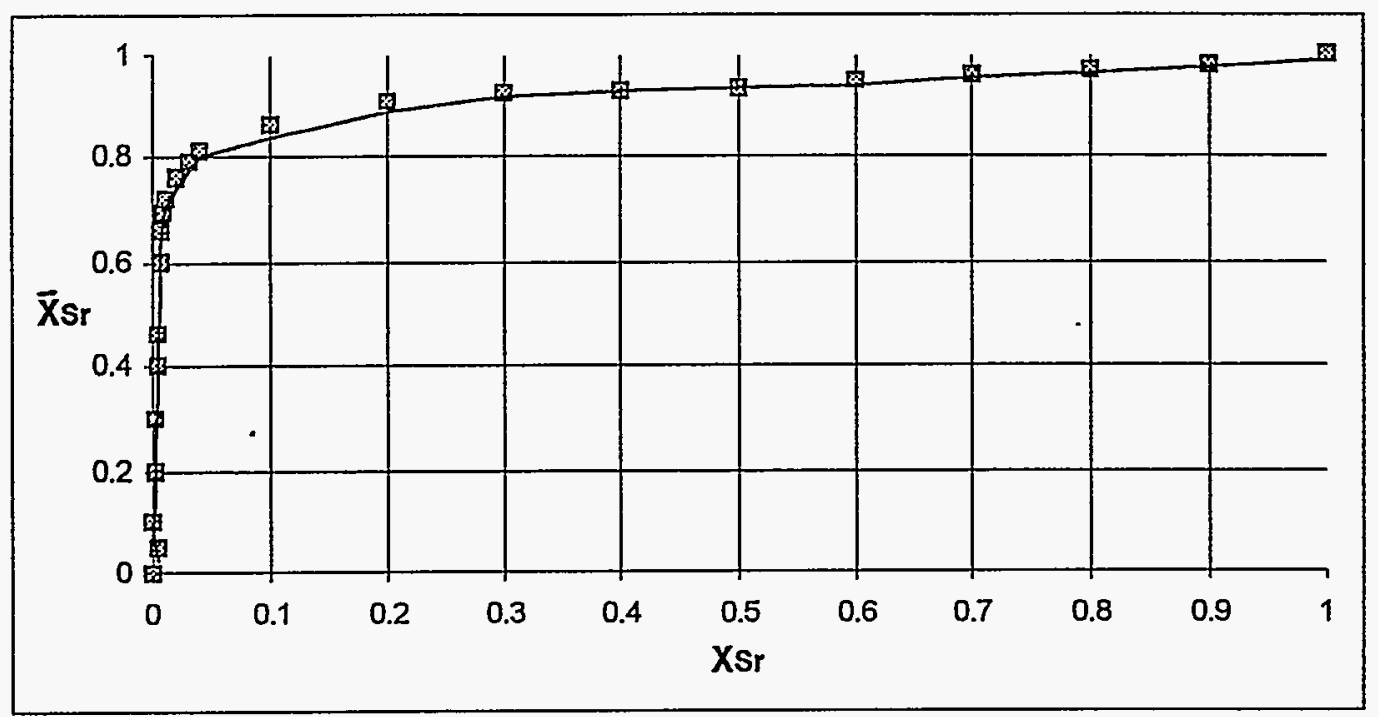

Figure \#2 Sorption Isotherm: Ni-Sr Nonscents

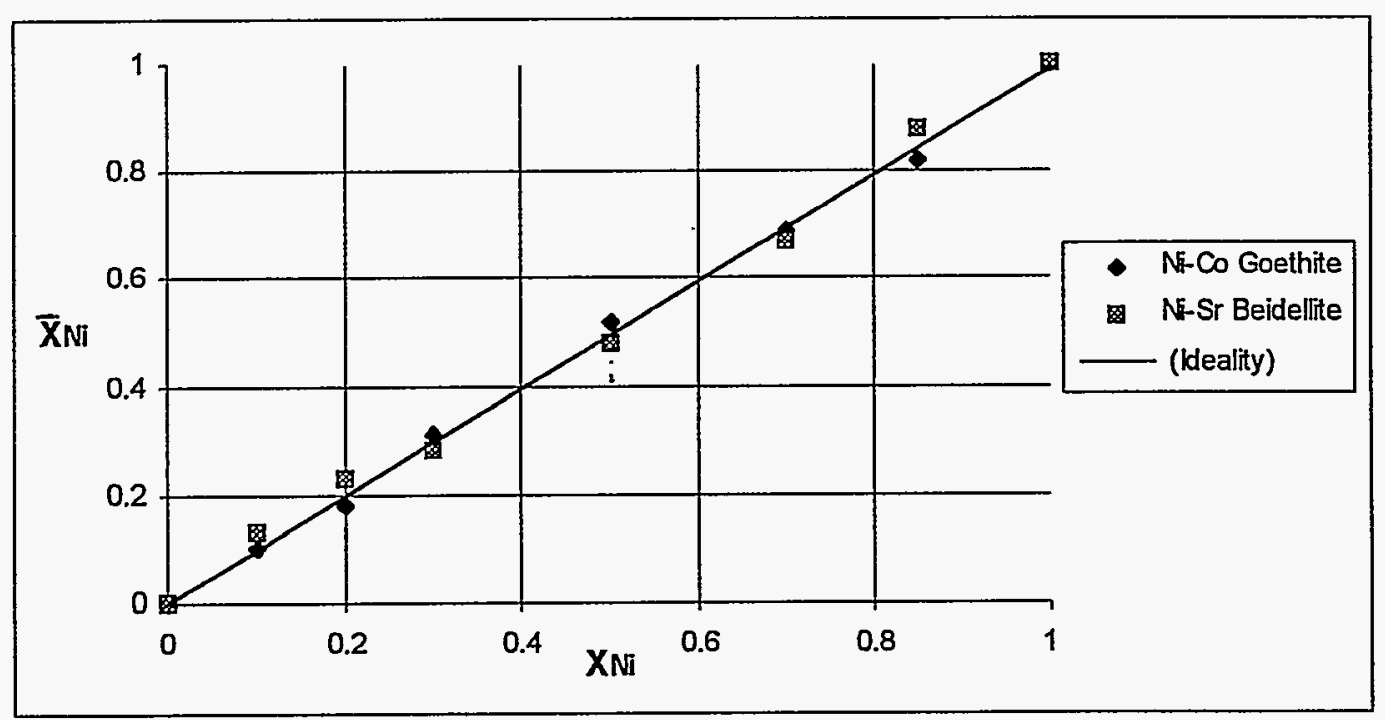

Figure \#3 Sorption Isotherm: Ni-Sr Beidellite \& Ni-Co Goethite 


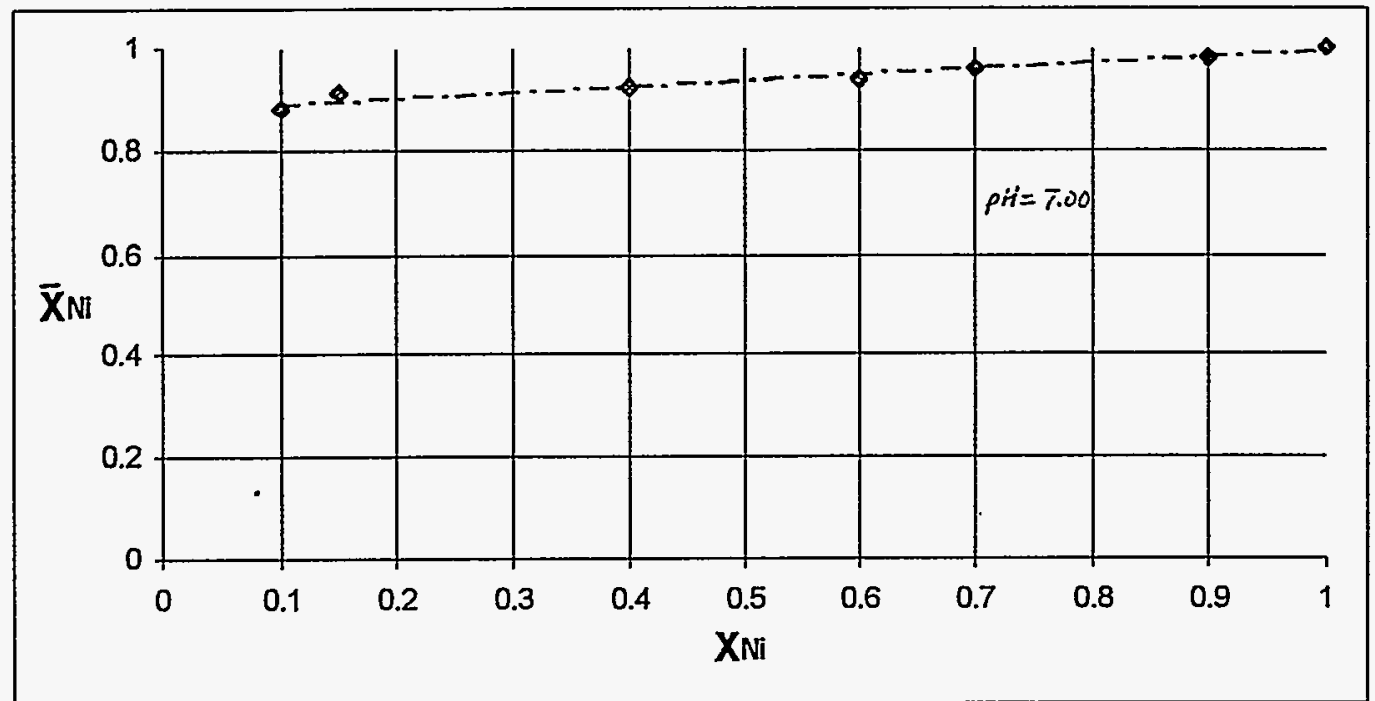

Figure \#4 Sorption Isotherm: Ni-Sr Goethite

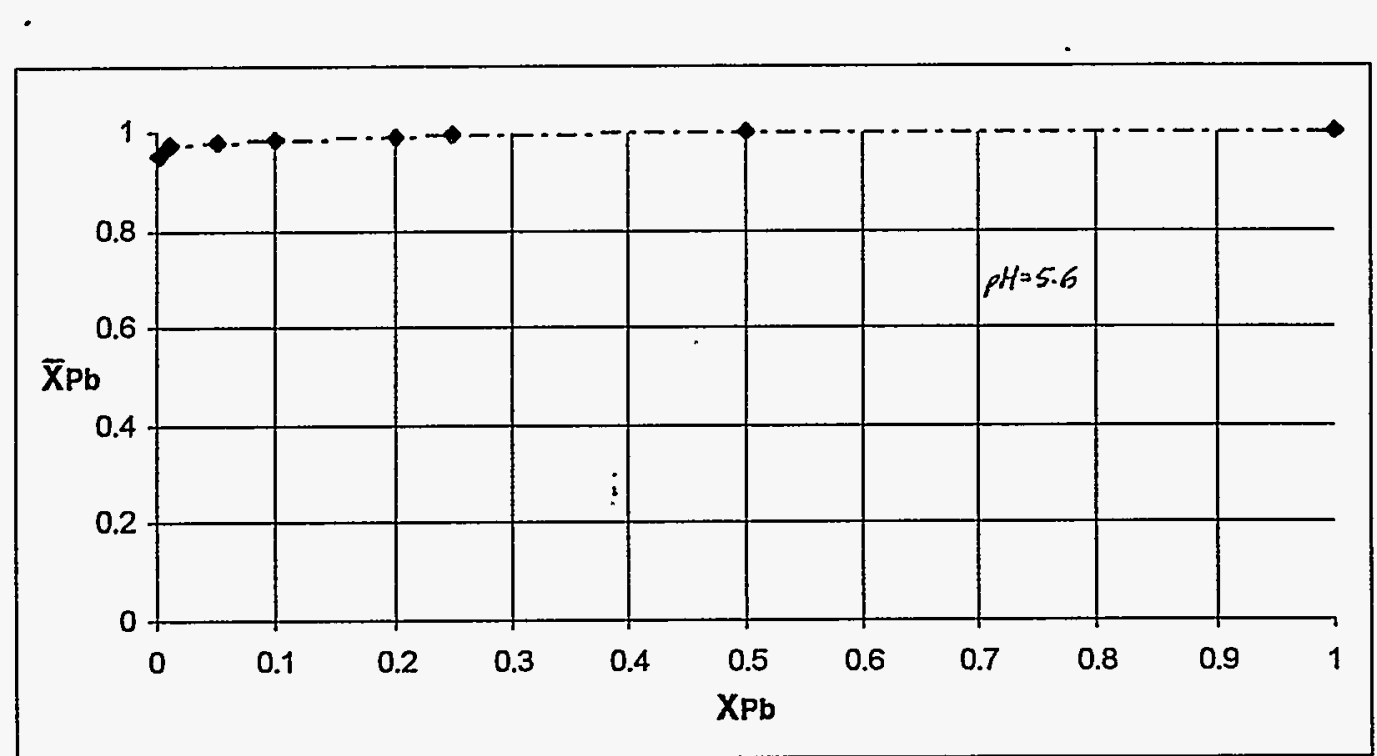

Figure \#5 Sorption Isotherm: Pb-Ni Goethite 


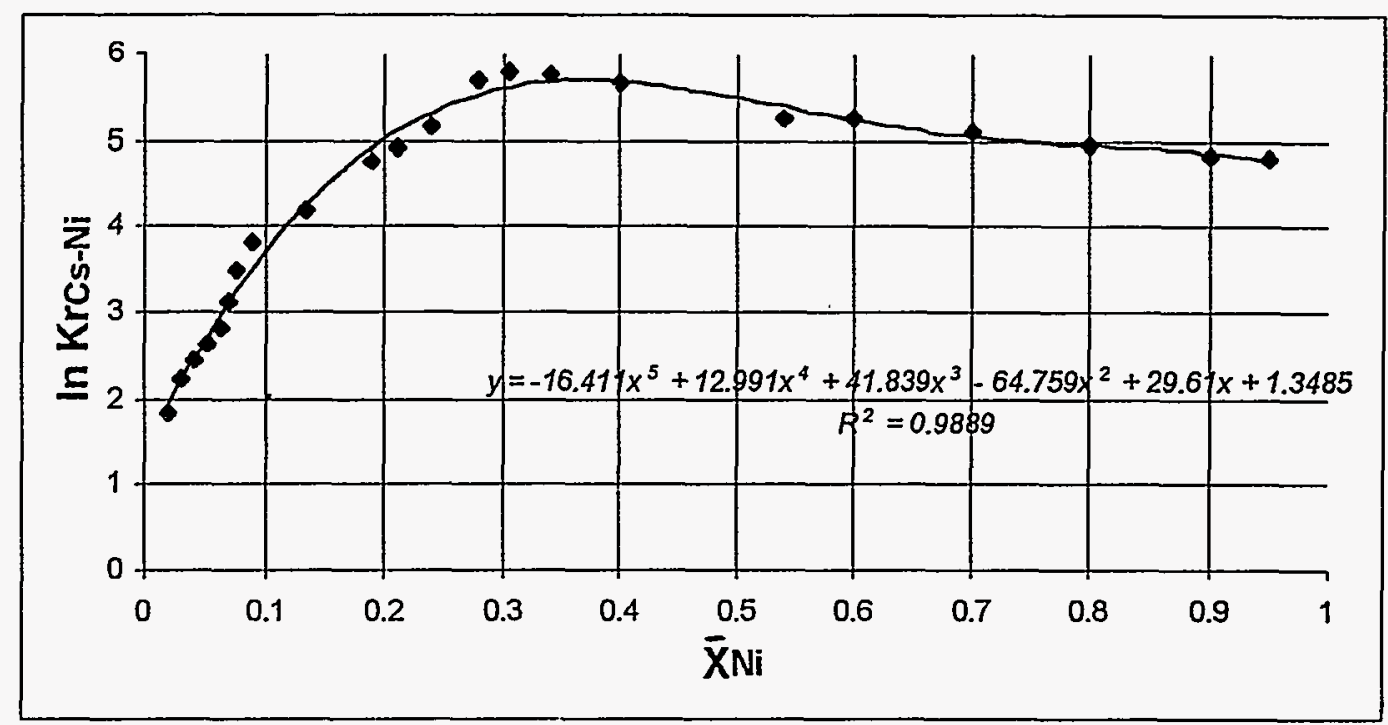

Figure \#6 Rational Selectivity Coefficients vs. the Solid-Phase Fraction of $\mathrm{Ni}_{2}^{2+}$

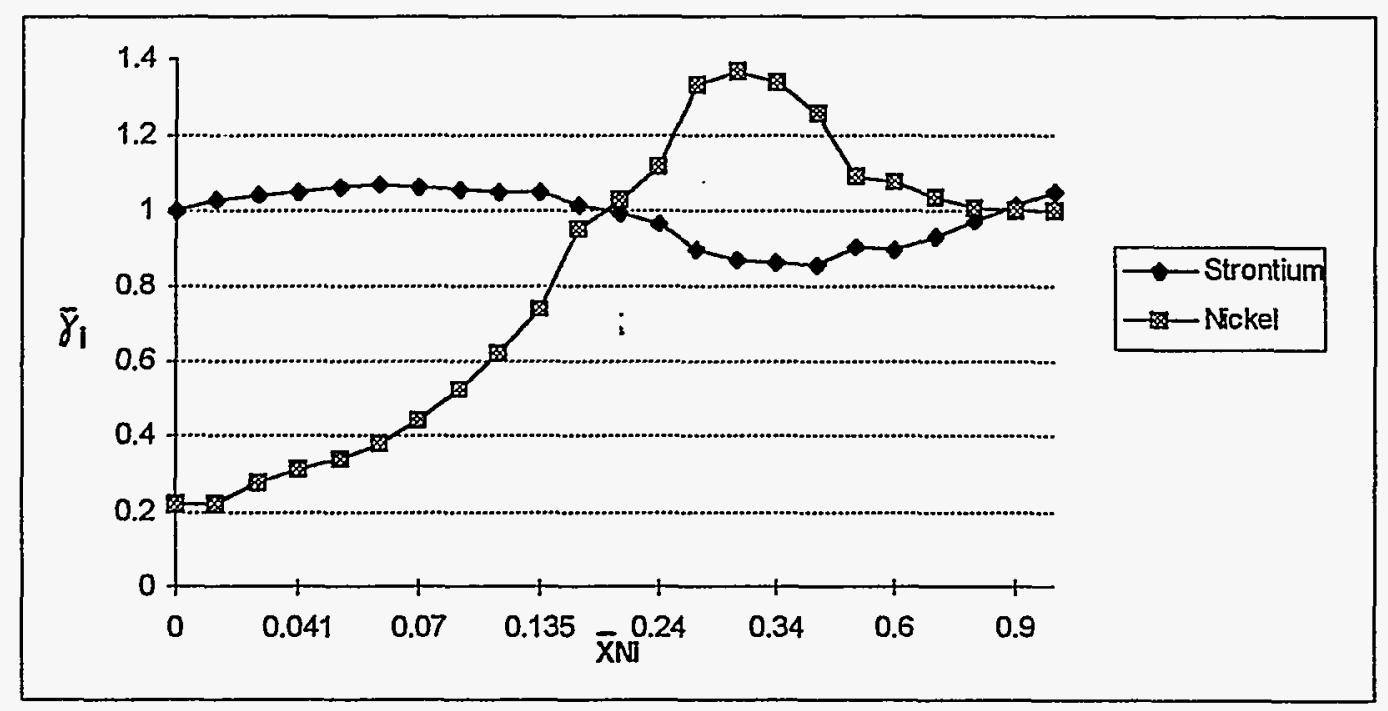

Figure \#7 Solid-Phase Activity Coefficients vs. the Solid-Phase Fraction of $\mathrm{Ni}^{2+}$ 
1. Berry, L.G. Mineralogy. W.H. Freeman and Company, New York, Second Edition (1983) pp. 319-320.

2. Gains, G.L. and Thomas, H.C. "Adsorption Studies on Clay Minerals II. - A Formulation of the Thermodynamics of Exchange Adsorption", Journal of Chemistry and Physics. 21, (1953) pp. 714-718.

3. Perry, R.H. and Green, Don. Perry's Chemical Engineers Handbook McGraw Hill, New York, Sixth Edition (1984) Section 16.

4. Rao, M.G., Das, P.C., Honga, E.U., "Effect of Solid-Phase Selectivity on Sorption of Cobalt and Strontium by Zeolited Tuff", Proceeding of the Third International Conference, High Level Radioactive Waste Management, Vol.2, pp 1496-1503, 1993.

5. Thomas, Kimberly W., "Summary of Sorption Measurements Performed with Yucca Mountain, Nevada Tuff Samples and Water from Well J-13", LANL Report LA 10960-MS, Dec 1987.

6. "Ion Exchange". Encyclopedia of Chemical Technology, Vol. 11, John Wiley \& Sons, New York, (1966) pp. 870-874.

\section{DISCLAIMER}

This report was prepared as an account of work sponsored by an agency of the United States Government. Neither the United States Government nor any agency thereof, nor any of their employees, makes any warranty, express or implied, or assumes any legal liability or responsibility for the accuracy, completeness, or usefulness of any information, apparatus, product, or process disclosed, or represents that its use would not infringe privately owned rights. Reference herein to any specific commercial product, process, or service by trade name, trademark, manufacturer, or otherwise does not necessarily constitute or imply its endorsement, recommendation, or favoring by the United States Government or any agency thereof. The views and opinions of authors expressed herein do not necessarily state or reflect those of the United States Government or any agency thereof. 